\section{Lowell Gustafson}

\section{Welcome to the Journal of Big History}

Welcome to the first issue of the Journal of Big History. The International Big History Association introduces this new journal to take the most recent step towards advancing the field of big history. Beginning the journal has been seven years in the making.

In 2010, Walter Álvarez, the renowned geologist, led a seminar held at the Osservatorio Geologico di Coldigioco (Geological Observatory of Coldigioco). He brought a small group of big historians just outside of Gubio, Italy, to one of the places where there is a thin line of iridium in a mountain side. This iridium provides evidence that tells us about the end of the non-avian dinosaurs 65 million years ago and the opening for mammals to evolve into a variety of species, including humans. Back at Coldigioco, Álvarez also explained how those same mountains had greatly influenced Italian and European history and culture. He demonstrated how the human past is embedded in a much longer global and universal past.

By 2010 many scholars worldwide shared a passion for big history. Scientists, humanists, and social scientists felt a need to form a professional organization in order to structure future discussions and investigations. They recognized the importance and the difficulties of a highly interdisciplinary field whose purpose was to investigate the integrated history of the cosmos, Earth, life, and humanity, using the best available empirical evidence and scholarly methods. The outcome of the meeting in Italy was the founding of the International Big History Association (IBHA).

Plans began immediately to organize conferences where big historians could share and discuss their findings with each other. Since 2010 IBHA has organized three conferences, with a fourth scheduled for 2018, and has published a regular bulletin. These initiatives aimed at developing the still new field of big history.
In the 1970's scholars from many disciplines began piecing together an evidence-based narrative that began - as best as we know now 13.8 billion years ago. We are able to trace this account from almost immediately after the big bang, to the emergence of protons and neutrons each from three quarks, the formation of hydrogen and helium atoms 380,000 years later, the first stars and galaxies, the formation of chemicals, supernovae, the accretion of Earth 4.5672 billion years ago, the first living organisms within a few hundred million years of that, the great increase in complexity of life forms, the eventual evolution of humans about 200,000 years ago, and the development of increasingly complex social, economic, and political cultures over the past 12,000 years. On this evidence we can project possible scenarios of the future.

No one person could possibly master all the fields necessary to produce this achievement. Only by working together, learning from each other, and building on earlier work could scholars from many disciplines start to connect the dots among the disciplines.

Universities have long been dedicated to the pursuit of a universe of knowledge. Yet the many disciplines that exist within universities and the many subfields that exist in each discipline do not yet all fit together neatly. Often a discipline, or a subfield, tries to build impenetrable walls around itself, protecting its own isolation, and budget lines. Academic silos are sometimes as resistant to forming connections with each other as protons are to each other in the absence of sufficient pressure.

Still, some scholars continue to forge intellectual relationships and build a coherent account of the entire known past. Marcelo Gleiser, professor of physics and astronomy at Dartmouth College, uses the analogy of a painstakingly constructed island of knowledge whose shoreline borders on what 
we do not yet know or understand. The analogy brings to mind the island continent of Australia, where the new field was named by David Christian at Macquarie University a quarter of a century ago.

Gleiser's analogy of an island of knowledge includes the efforts by many people to increase the size of the island by making intellectual advances. The human island of knowledge has increased over the past millennia, centuries, decades, and years. With this in mind, it is fitting that one of the main centers of big history has been at the University of Amsterdam in the Netherlands, with its history of forming its own land from the sea beyond itself through the ingenuity and effort of its own people.

Rather than providing the intellectual vision for a single island of knowledge, universities are sometimes sites for largely separate disciplines and departments. Each scholar lives on one of a number of islands that are barely within sight of each other. The expertise of disciplines and intellectual focus on specific issues are without doubt highly valuable. They have produced the data from which big history has emerged. Each discipline offers its own sets of analyses and understandings. But by themselves, none of them could construct the comprehensive narrative that they can together. Filling in the spaces between the islands of knowledge, connecting each of them, and pushing out their borders into the unknown, are no easy tasks. Developing big history requires both advances within established disciplines and intellectual synthesis.

With each new addition to the island of knowledge, with each answer found, with each improvement to our understanding, new questions are raised. We become even more aware of what we still do not know. To push out our borders and to build the connections among our various islands, we will need to address many still unanswered questions. Just a very few of these might include: How did the universe begin when it did? Can we find evidence for other universes, or fundamentally different kinds of reality than exist in this universe? What is nature if we cannot observe formative parts of it without that observation changing them? What do the smallest components of our own universe tell us about the nature from which we have emerged and that sustains us for now? Exactly how did life originate?

How can we connect what we do know to provide a better account of where we have come from and who we are now? Why does complexity sometimes develop, while often it does not? Some of the hydrogen and helium that floated in unimaginably huge clouds soon after the Big Bang became stars, Earth, single cells, mammals, and finally us. The 100 billion neurons with their trillion synapses make each of our brains the most complex matter in the universe of which we know. But huge clouds of the simplest elements remain. Unimaginable numbers of single cell organisms continue to survive perfectly well without any increase in their structural complexity.

Our complex brains have permitted - and have been stimulated by - the increasingly complex relationships among humans in kinship groups, villages, cities, empires and nations, and global or human structures. Yet, earlier and simpler compositions often continue, and more complex ones often return to simpler ones. In recent times, we have seen regional and global networks being challenged by populist ones which exhibit properties that sometimes seem similar to tribal ones. Our ideas of what it means to be human within our many sub-categories may have as many layers and components as the rest of nature from which we have evolved.

We - and the rest of nature - remain an unfinished puzzle. Our over-arching narrative has many gaps and questions. Much remains to investigate and ponder, share and debate. The more we know and understand, the more we butt up against what we do not know and wake up at night trying to figure out. 
The Journal of Big History appears as the result of cooperation by many people. Long discussions early on among David Baker, Cynthia Brown, David Christian, Andrey Korotayev, Esther Quaedackers, Barry Rodrigue, Fred Spier, and the late Ji-Hyung Cho, provided the foundation for the subsequent proposal for a journal that was discussed, developed, and approved in 2016 by the IBHA Board of Directors.

Heathe Kyle Yeakley has generously offered much technical advice and service. We have depended on the careful work of many reviewers and the journal's editorial board. The ideas, careful editing, and commitment of Esther Quaedackers and Cynthia Brown to every stage of producing the journal are indispensable. The scholarship of all those who submit manuscripts is the key to the success of the journal.

The IBHA will continue to organize conferences that will encourage traditional and innovative approaches to big history. It will continue to present provocative pieces in its bulletin, Origins. And now, it introduces this new journal to advance the field of big history.

Welcome to the shoreline of the islands where we live now. In this journal we will seek to cultivate each island of evidence-based knowledge, fill in the open spaces between them, and maybe expand our shoreline from time to time.

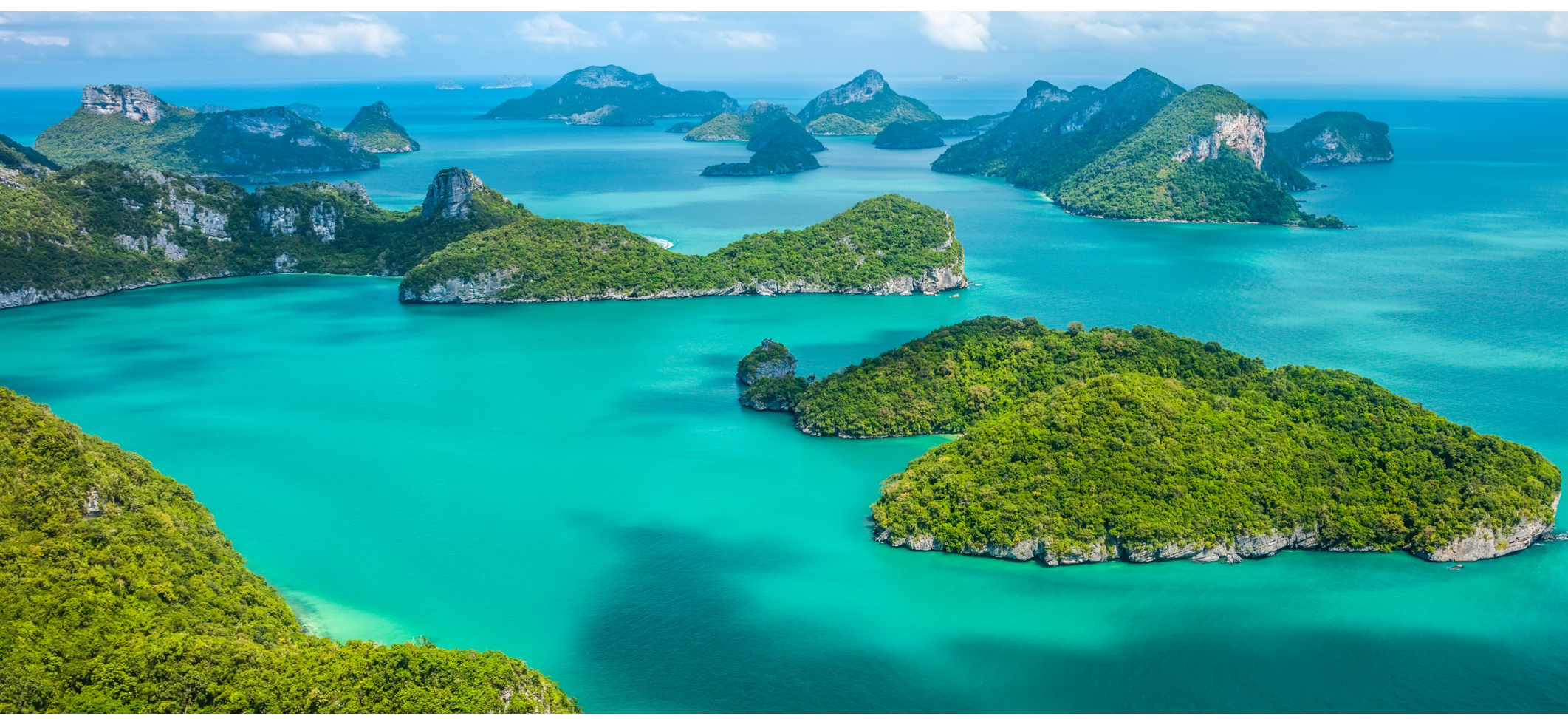

\section{Note to Contributors}

In this journal, we seek to share new scholarship about big history. Please submit your manuscripts to Lowell Gustafson atjbh@ibhanet.com or at journalofbighistory. org. Manuscripts will go through a double blind review in which submitters and reviewers will not be informed of each others' names. Articles should be approximately 10,000 words in length, readable by scholars across disciplines, and based on evidenced and logical thinking. Please use the
Chicago manual of style where possible, but in our highly interdisciplinary field, you may use styles that are traditional in your disciplines.

Books to be reviewed may be sent to Cynthia Brown, 139 Stonewall Road, Berkeley, CA 94705. Book reviews should be sent to Cynthia S. Brown (cbcynthia@earthlink.net) and John Mears (jmears@mail.smu.edu). 